count was taken at the end of the autumn term. This change has had an appreciable effect on the statistics of part-time students but not on the numbers of fulltime students and of staff. Only those part-time students in universities at the end of the autumn term are recorded now - this has resulted in a drop in their numbers in 1965-66 compared with the previous academic year. Other changes in the 1965-66 statistics have included the reclassification of the staff and students into more detailed subject groups, and the inclusion of all academic staff : those financed entirely from university funds as well as those receiving money from outside sources. All this extra and more detailed information explains the bulkiness of these statistics. The new arrangement also makes direct comparisons with previous years more difficult.

A further difficulty is that, for the first time, the former Colleges of Advanced Technology and the Heriot-Watt College are included in the UGC's list of forty-four university institutions in receipt of exchequer grants. In many ways, the 1965-66 figures confirm those published in Statistics of Education, 1965, Part Three, compiled by the Department of Education and Science (HMSO, 1967). In fact the next issue of Returns from the UGC (for 1966-67) will be amalgamated with the Statistics of Education from the DES. Lord Robbins's prediction of 173,200 full-time students in universities and CATs in 1965-66 was not confirmed by the actual numbers in that year. His estimate was, in fact, about 4,000 too manythere were only 169,486 full-time students in Great Britain in 1965-66. Contrary to general opinion, Lord Robbins's estimate for the academic year 1966-67 was also too high-186,900 when actual figures were about 184,200. The change-over from his figure being too high to being too low is, however, taking place this academic year. Provisional figures of full-time university students from the UGC (from figures compiled in October 1967) show that there are about 199,700 university students at the moment-Robbins estimated that there would be some 196,500.

Out of the 169,486 students in 1965-66, there were 28,428 postgraduate level students (including those taking postgraduate courses in teacher training). In Britain as a whole postgraduates represented some 17 per cent of the total student population; in England and Wales alone, the proportion was about 18 per cent, while in Scotland it was about 9.5 per cent. The provisional figures for 1966-67 and 1967-68 do not show any marked increase in the proportion of postgraduates among university students-it is around 17 per cent for Britain as a whole, while figures for England and Wales, and Scotland, are about 19 and 10 per cent respectively.

The number of overseas students has continued to increase $(9 \cdot 4$ per cent in $1965-66)$, but as a percentage of the total student population represents a marked decline from the peak of 11.5 per cent in 1961-62.

The recurrent income of universities in the year under review amounted to $£ 164 \cdot 7$ million. If the former CATs and the Heriot-Watt University are omitted this represents an increase of $£ 22$ million over 1964-65. Income from fees is continuing to fall, amounting to only $7 \cdot 4$ per cent of the total. Recurrent expenditure of universities in 1965-66 amounted to $£ 160$ million, of which 36.5 per cent was spent on salaries and $10 \cdot 1$ per cent on wages of departmental staff. Departmental maintenance, and research and other types of specific expenditure, took $11 \cdot 8$ and $14 \cdot 0$ per cent, respectively. Some of the headings for the recurrent expenditure have been changed and so valid comparisons with previous years cannot be made.

\section{Designing for Wind}

THE largest wind tunnel available in the United Kingdom for the study of industrial aerodynamics is now in opcration at the Marchwood Engineering Establishment of the Central Electricity Generating Board. This is an appropriate place to find a large wind tunnel, for the CEGB was the victim of the most celebrated civil engineering failure in recent years-the collapse of the cooling towers at Ferrybridge $C$ power station in 1965. The CEGB is quick to point out that the wind tunnel was planned before the Ferrybridge collapse, although it has come into commission more recently. The tunnel, which cost $£ 100,000$, should be particularly useful for studies of large arrays of cooling towers, or scale models of entire structures such as power stations; other wind tunnels in the United Kingdom are too small for this kind of investigation.

The picture shows the great size of the working area in the slow section of the tunnel. This section is 80 feet long, 30 feet wide and 9 feet high, and air speeds of up to $50 \mathrm{feet} / \mathrm{sec}$ can be reached. It comes as something of a surprise, however, to be told that the real purpose of the tunnel is for research at very low wind velocities, of only a few feet per second.

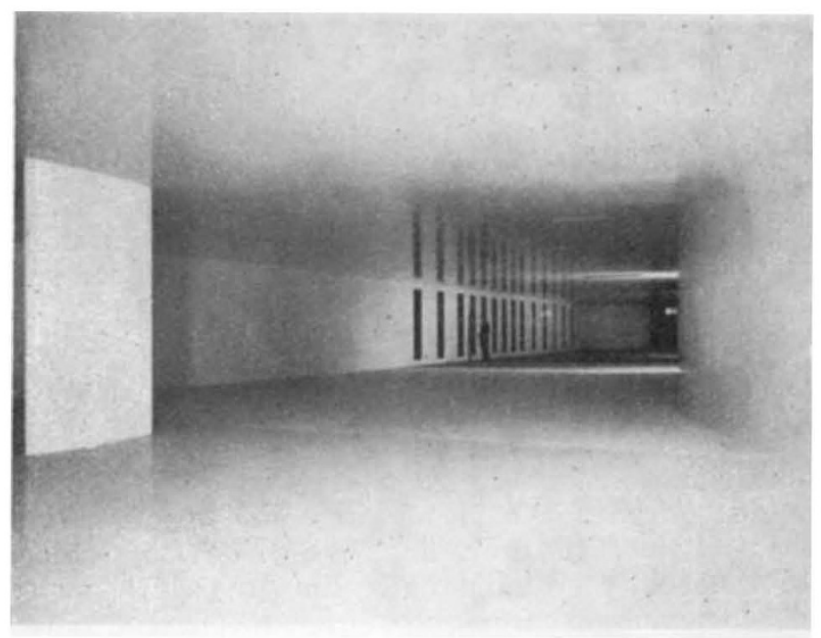

The large wind tunnel at Marchwood (CEGB).

The difficulty here is that atmospheric disturbances outside the wind tunnel can seriously influence the wind speed within the tunnel-this has been overcome at Marchwood by drawing the air into the tunnel through an elaborate baffle which smooths out the disturbances. The tunnel is the shape of a bottle, the neck of which serves as a fast region 16 feet long, 7 feet wide and the same height as the slow section. In this region speeds of $200 \mathrm{feet} / \mathrm{sec}$ can be reached.

Industrial aerodynamics differs in various ways from the sort of work carried out with aircraft. In the case of tall structures, the top of the building, which penetrates through the atmospheric boundary layer, is subject to greater stress than the lower parts 
of the building. The tunnel at Marchwood is provided with the means to simulate this boundary layer. The fluctuations in the wind velocity are also important, because they represent a much greater proportion of the total loading than is the case with aircraft. Two projects under study at Marchwood are concerned with the dynamics of current-carrying cables and the effect of reducing the height of a gas turbine exhaust stack. If the stack height could be reduced, money could be saved, but the danger is that the hot gas would be drawn back into the turbines and the building ventilation system.

Another wind tunnel undergoing trials at Marchwood is concerned with the other extreme of wind speeds-the supersonic speeds experienced by turbine blades. This is a closed circuit tunnel capable of testing turbine blades up to Mach 2. As turbines increase in power, the blades must get longer, and this means that the tips of the blades will be moving at even greater speed. The new tunnel, run by an electric motor which drives an Avon compressor (bought cheaply on the second-hand market), will help to build up experience of conditions like these before the very large machines come into operation.

\section{Wind-borne Foot and Mouth Disease}

THE London Times (April 23) has reported that meteorologists at the Meteorological Office at Bracknell have analysed the spread of foot and mouth disease in Cheshire in an outbreak in 1952 and concluded that wind and rain were the main vectors. 'The disease affected 160 farms, and with only one exception every outbreak occurred downwind of an already infected farm during rainy weather. In most cases the rain was at night. After eight consecutive dry nights, the epidemic declined. The meteorologists are also said to have analysed the relationship between the prevailing wind and the distribution of scattered outbreaks along the Kent and Sussex coasts in the spring and summer of 1952 .

After the initial outbreak at Oswestry in October last year, there were fifteen wet nights out of the first seventeen, and the pattern of spread of the disease reflected the changes in wind direction for at least the first four weeks of the epidemic. A computer is being used to analyse the epidemic. It is also rumoured that the analyses of the prevailing wind patterns in October 1967 make it very unlikely that the virus which started the epidemic came from the continent. That, of course, was the conclusion of the Reid report. Publication of the details of this research has been officially delayed until they have been presented to the Northumberland committee which is collecting evidence for its inquiry.

\section{Research in Jeopardy}

UNLESS more funds can be raised, research at the London Institute of Ophthalmology will have to be severely curtailed in 1969 when the current grants, which are supposed to last until 1970 , will have been spent. The "Fight for Sight" campaign has so far only produced $£ 460,000$ out of a target of $£ 1$ million and, unless another $£ 0.5$ million is raised, the outlook for research is bleak. There is now a freeze on the numbers of staff. As members leave--there are 176 on the staff,
56 of whom are academic staff-they are not usually being replaced, and no money is available for modernization of the institute's laboratories and very little for apparatus.

The institute, one of fourteen specialized medical institutes in London University, was formally established in 1948 on the recommendation of the Goodenough report, although it had in effect been formed two years earlier. Since then it has become one of the leading centres in the world for research into vision and has been a model for comparable institutes in India, Egypt and Australia. It is an entirely postgraduate institution and is responsible for all the postgraduate teaching of ophthalmology in London. Ninety-five per cent of the students, however, come from abroadchiefly from Africa, Asia and the Middle East-and there is a queue of overseas applicants awaiting places.

The University Grants Committee finances the teaching. In 1967-68 it gave the institute $£ 171,050$, 48 per cent of its total budget, for teaching and $£ 7,000$ for apparatus, and it is virtually certain that the grant for 1968-69 will be about the same-in other words, insufficient. The research, which ranges from investigations of eye pigments at the molecular level to the use of lasers in eye surgery (see Nature, 216, 535; 1967), is financed by specific grants from foundations and from the institute's own income. In 1963 the institute launched its first public appeal, "Fight for Sight", which is in keeping with the UGC policy of encouraging financial independence. To continue research at the present levels, let alone expand, the institute needs $£ 1$ million but, perhaps surprisingly, granted the emotive appeal of blindness, it has only raised about half this sum. The institute's research would be bound to benefit if the proposal of the Todd report, that the institute should merge with St Bartholomew's Hospital, the London Hospital and Queen Mary's College, were put into practice. And the perhaps justifiable fears that in such a merger the institute's work would be submerged by undergraduate demands are no real obstacle. But a merger would not solve the institute's financial problems- the public will have to be persuaded to do that.

\section{Screening for Cancer}

An aid to the efficiency of cytologists in their analyses of cervical smears is now being given field trials. In collaboration with doctors in Oxford (see Lancet, February 17, 359), Vickers Ltd have developed a cytological screening instrument to scan smears and pick out those with evidence of a possible pre-cancer statean in situ carcinoma. The Vickers cytology screening apparatus (VCSA) is based on the theory, put forward by $\mathrm{Dr}$ R. A. Diamond in his Oxford BSe thesis last year, that the presence of more than 12 nuclei larger than $12 \mu$ in diameter in a smear is indicative of a precancer state. The VCSA spreads out cells from a cervical smear in a thin line along transparent tape, using about 2.5 feet of tape for each sample. Standard staining and fixing techniques used for microscope slides are carried out automatically. The treated tape is then fed through a microscope which is preset so that whenever a nucleus larger than $12 \mu$ in diameter is found by the automatic scanner, a hole is punched in the tape. A cytologist can then replay the tape to find the potentially dangerous cells and 